\title{
Overview on Nanotechnology: The Future of Seawater Desalination
}

\author{
Dr. Amrita Khatri \\ Professor in zoology, MJB Govt. P.G. College, Moti Tabela, Indore, India
}

\begin{abstract}
It has been well documented that many societies around the world are currently experiencing the consequences of water scarcity, and this scarcity is likely to be one of the major resource crises of the 21st century. While over 70 per cent of the Earth's surface is covered by water, most of it is unusable for human consumption. Freshwater lakes, rivers and underground aquifers represent only 2.5 per cent of the world's total freshwater supply. Unfortunately, in addition to being scarce, freshwater is also very unevenly distributed. The United Nations has compared water consumption with its availability and has predicted that by the middle of this century between 2 billion and 7 billion people will be faced with water scarcity. Nanotechnology, offers the potential of new nanomaterials with the nanoscale (1-100 $\mathrm{nm})$, for desalination of sea water. Due to its unique activity towards intractable pollutants and application flexibility, a research is going on many nanomaterials specially graphene. Recognizing the limitations of conducting crossnational research on water resources, presently an overview on desalination by nanotechnology with special reference to Graphene nanomaterial has been chosen for study. It is observed that economic development and connections to the global economy are key forces influencing water consumption.
\end{abstract}

Keywords: Nanotechnology, graphene, nanomaterials ,water scarcity, desalination

\section{Introduction}

Availability of total fresh water in the form of rivers lakes and aquifers is only $0.6 \%$. Access to clean water is a bigger problem for exploited and under industrialized areas than hunger. Within the next two decades, the average supply of water per person will drop by one third, possibly condemning millions of people to severe dehydration and avoidable premature death. The water contains low concentrations of dissolved salts is to be considered safe only for drinking and agriculture (Wagner, 2007).The achievable diminution in energy demand by high-tech seawater desalination technologies, the probable role of advanced materials and innovative technologies in improving performance, and the sustainability of desalination as a technological solution to global water shortages has been reviewed (Elimelech \& Phillip, 2011).

Sea water and brackish water desalination technologies can be of great assistance to scrap the warning of constantly increasing demand of water due to invasion in inhabitant's growth, industrialization, pollution of available fresh water resources and climate change. Most of the traditional technologies such as solvent extraction, activated carbon adsorption and common chemical oxidation, are very effective ,costly and time consuming (Cloete et al. ,2010). Nanotechnology promises to dramatically enhance many water purification or desalination technologies. This study aims to provide a review of the state of desalination by nanotechnology.The nanomaterial graphene is choosen as the graphyne sheet exhibits promising potential for nanoscale desalination to achieve both high water permeability and salt rejection rate.

Graphene has amazing properties as it is one million times thinner than a human hair, 300 times stronger than steel and 1,000 times more conductive than silicon, but six times lighter. Graphene-based nanomaterials have many promising applications in energy-related areas. The Graphene conducts electricity better than copper. It is almost perfectly transparent since it only absorbs $2 \%$ of light. It impermeable to gases, even those as light as hydrogen or helium, and, if that were not enough, chemical components can be added to its surface to alter its properties. Graphene sheets with precisely controlled pores have potential to purify water more efficiently than existing methods.( Chandler, 2012).

Desalination has long been linked with conversion of brackish or seawater into potable (drinkable) fresh water by conventional methods. But a host of new technologies are being developed that not only are improving traditional desalination but opening up new frontiers in reusing everything from agricultural water to industrial effluent. For some parts of the world desalination of seawater is an important option for accessing fresh drinking water. In 2007 the estimates were that worldwide desalination reached 30 billion liters a day. But the cost of that desalination was at the exorbitant levels of $\$ 0.50$ to $\$ 0.85$ per cubic meter.( posted by Johnson, 2012). Because of this huge expense, most desalination production remains in the oil-producing countries of the Persian Gulf, where they can afford the huge energy costs. Outside of the Middle East, the predominant method for desalination is Reverse Osmosis (RO), which is only slightly less energy consuming and expensive than MSF processes. Currently, RO depends on comparatively thick membranes that effectively block the salt ions when water molecules are hydraulically pushed through them.

Graphene, a structure of pure carbon just one atom thick with its carbon atoms arranged in a hexagonal array, is one of the strongest materials known. In the process envisioned by the MIT researchers, which was published in the journal Nano Letters, one-atom-thick grapheme with nanometersized pores would replace those membranes. Because the graphene is a thousand times thinner than the traditional membrane materials it requires far less force-and therefore energy - to push the water molecules through it. Since of its large surface area per mass, it is used for making super 


\section{International Journal of Science and Research (IJSR) \\ ISSN (Online): 2319-7064}

Index Copernicus Value (2013): 6.14 | Impact Factor (2014): 5.611

capacitors that can easily be bent, folded, or stretched to as much as 800 percent of its original size ( Zang et al.,2014), This material can be crumpled and flattened up to 1,000 times .CVD-grown single layer graphene undergoes rapid photochemical oxidation in the presence of ultraviolet light and oxygen. (Zhao et al., 2012). The graphene membrane allowed rapid transport of water through the membrane and rejected nearly 100 percent of the salt ions, e.g., positively charged sodium atoms and negatively charged chloride atoms.

\section{Methodology and Opinions of Various Researchers}

There are several experiments performed by various researchers based on nanotechnology for desalination. Nanotechnology-based applications are still in R\&D stage. None of them has reached up to industrial levels so far. (Hillie \& Hlophe, 2007; Theron et al., 2008).

It has been reported that by ion concentration polarization method, sea water can be converted into fresh water. In this a constant watercourse of sea water is divided into desalted and concentrated streams when it is passed through ionselective membranes. To implement this approach, a simple micro fluidic device was fabricated and shown to be capable of continuous desalination of sea water ( $\sim 99 \%$ salt rejection at $50 \%$ recovery rate) at a power consumption of less than 3.5 $\mathrm{Wh} \mathrm{l}^{-1}$, which is comparable to current state-of-the-art systems. Rather than competing with larger desalination plants. The method could be used to make small- or medium-scale systems, with the possibility of batterypowered operation (Kim et al, 2010).

Researchers at MIT (2012) \{Massachusetts Institute of Technology are looking to replace the membrane materials used now in RO with nanoporous graphene. . Graphene has been among the fastest growing areas of nanoscience and technology over the past five years. This two-dimensional form of carbon has been found to have remarkable electronic, optical, mechanical and chemical properties, and continues to be the subject of intense research.

In the most recent development, two physicists, Daniel Torrent and José Sánchez-Dehesa of the Polytechnic University of Valencia in Spain(2012) prepared an auditory edition of the speculate substance graphene by simply drilling a honeycomb pattern of holes into a plastic sheet. Each hole represented a carbon atom. They have spotted "Dirac cones" - a distinguishing feature in the electronic band structure of graphene - in sound waves that propagate on the surface of the plastic. As a stand-in for graphene, they used a compound called methyl methacrylate, which in the form of poly methyl methacrylate is more commonly known as Plexiglass.

A company, Locked Martin, has developed perforene from graphene(2013), which has been awarded a patent for it .It is a molecular filtration material intended to fulfill increasing demand for potable water. It can remove sodium, chlorine and other ions from sea water and other sources. It can desalinate sea water using only $1 / 100^{\text {th }}$ of the energy of existing desalination processes.
Recently, high quality graphene crystals have been synthesized from solid waste plastic as carbon source in an ambient pressure (AP) chemical vapor deposition (CVD) process(Sharma et al.,2014)

Experiments were done by a group of researchers at department of Energy's Oak Ridge National Laboratory. They demonstrated an energy- proficient desalination technology in which a carbon honeycomb one atom thin porous membrane, made of strong, slim graphene-was used. To make graphene for the membrane, the researchers flowed methane through a tube furnace at 1,000 degrees $\mathrm{C}$ over a copper foil that catalyzed its decomposition into carbon and hydrogen. The chemical vapor deposited carbon atoms that self-assembled into adjoining hexagons to form a sheet one atom thick. That was the easy part. The next step involved putting the graphene sheet on a chip of silicon nitride, and exposing it to oxygen plasma in order to force out selected carbon atoms. That left a hole or pore in the sheet. The team was able to tune the number and size of the pores by varying the length of time that the carbon sheet was exposed to the plasma. ( Surmedh et al. 2015)

The scientists, Kieran Mullen, Bruno Uchoa, and Daniel T. Glatzhofer at the University of Oklahoma, have published a paper on the proposed hyper-honeycomb and related structures in a recent issue of Physical Review Letters. 2015 .Scientists have proposed a new family of structures that are three-dimensional (3D) variations of graphene, the simplest example of which is called a "hyper-honeycomb." $\mathrm{T}$ he scientists also predict that, among its interesting properties, the hyper-honeycomb could potentially be even more stable than diamond".

The 2015 edition of the United Nations World Water Development Report (WWDR 2015), titled Water for a Sustainable World", has been launched at the official celebration of the World Water Day, on March 20,2015.The report provided a comprehensive overview of major and emerging trends from around the world, with examples of how some of the trend-related challenges have been addressed, their implications for policy-makers, and further actions that can be taken by stakeholders and the international community.

\section{Conclusion}

Increased demand for water is a global problem. In many parts of the world local demand is exceeding conventional resources. More economical use of water, reducing distribution losses and increased use of recycled water can help alleviate this problem but if there is still a shortfall then desalination of seawater or brackish water is a must.

Water scarcity across the world is serious and escalating issue and it is anticipated that impacts of global climatic change will only exacerbate this problem. Water desalination technology has become a significant player in the portfolio of drinking water supply options for meeting global demand. The global water desalination plant capacity is expected to continue to grow to nearly double digit rates over the next decade. 


\section{International Journal of Science and Research (IJSR) \\ ISSN (Online): 2319-7064}

Index Copernicus Value (2013): 6.14 | Impact Factor (2014): 5.611

So far the graphene desalination membrane has passed its tests with flying colors, achieving almost 100 percent rejection of salt ions while allowing water to flow through at a rapid pace. The use of methane in water purification particularly ironic, given that one of the major issues in natural gas fracking is water contamination from both fracking fluid and fracking wastewater disposal.

On the other hand, when you consider the growth of methane-rich, renewable biogassources, perhaps some day in the sparkling green future that super-efficient graphene desalination membrane can trace its roots to your friendly neighborhood hog farm.

The use of graphene and other carbon-based nanomaterials, such as carbon nanotubes, are growing rapidly.

Nanotechnology plays a great role in averting future water shortages. But hoping that the 'magic' of nanotechnology will solve all water problems is still far away to be true, because of the basic problems of accessibility to technologies, affordability, and nanotechnology-based applications are still in R\&D stage. None of them has been scaled up to industrial levels yet (Hillie \& Hlophe, 2007; Theron et al., 2008).

Desalination shouldn't be used as a quick fix to our water shortage problems. Conservation and recycling programs are usually much less expensive and less risky alternatives to building desalination plants. At the same time, recent studies have suggested graphene oxide may be toxic to humans, so it is important for regulators, such as the Environmental Protection Agency, to understand their potential environmental impacts before it is widely used.

\section{Future of Nanotechnology Desalination}

based

Although the cost of sea water desalination has decreased scientifically over the last few decades, it is still higher than conventional sources of drinking water supply. Existing fresh water sources and other alternatives like water conservation, recycling and reuse will not be sufficient to meet the rapidly increasing fresh water demand especially in drought affected and arid regions of the world .Unlike fresh water resources, the sea water is readily available and not affected by climatic and environmental conditions like drought or the vagaries of the weather .Hence sea water desalination will continue to offer a large potential for an abundant and regular supply of fresh and clean water and remain a significant component of the global portfolio of water supply options. There is much ongoing effort in the industry to make desalination more affordable and sustainable.

The use of methane in water purification particularly ironic, given that one of the major issues in natural gas fracking is water contamination from both fracking fluid and fracking wastewater disposal.

On the other hand, when you consider the growth of methane-rich, renewable biogas sources, perhaps someday in the sparkling green future that super-efficient graphene desalination membrane can trace its roots to your friendly neighborhood hog farm.

It may be assumed that by 2050 , humanity has achieved a water secure world, where every person will get adequate quantities of water of an acceptable quality from sustainable sources, to meet his basic needs and sustain his wellbeing and development. The human population will also be well protected from waterborne pollution and diseases and waterrelated disasters (The UNWWD Report, 2015)

\section{References}

[1] Chandler, D L(2012) A new approach to water desalination. MIT News

[2] Cloete, TE; de Kwaadsteniet M; Botes M; LopezRomero JM.( 2010) Nanotechnology in Water Treatment Applications. Norfolk, UK: Caister Academic Press;

[3] Dexter J (2012) Nanoporous Graphene Promises Affordable Water Desalination Nanoclast Posted 3 Jul 2012 | 15:22 GMT

[4] Elimelech, M. \& Phillip, W. A. (2011) The Future of Seawater Desalination: energy, technology, and the environment. Science 333, 712-717.

[5] Hillie T \& Hlophe M, (2007) Nanotechnology and the challenge of clean water, Nature Nanotechnology 2, 663 -664 .

[6] Kim S J, Ko S H, Kang K H \& Han J (2010) Direct seawater desalination by ion concentration polarization Nature Nanotechnology 5, 297 - 301 (2010)

[7] Massachusetts Institute of Technology. (2012) A new approach to water desalination. Retrieved from: http://newsoffice.mit.edu/2012/graphene-waterdesalination-0702.

[8] Massachusetts Institute of Technology (2014) Technique to create holes in graphene could improve water filters, desalination Journal Nanoletter.

[9] Sharma S; Kalita G; Hirano R; . Shinde SM; Papon R ; Ohtani $\mathrm{H}$ and Tanemura $\mathrm{M}$ (2014) Synthesis of graphene crystals from solid waste plastic by chemical vapor deposition Carbon 72:66-73

[10] Surmedh P S, Smirnov SN, Vlassiouk I V, Unocic RR,Veith GM,Dai S and Mahurin SM ( 2015) Water desalination using nanoporous single -layer graphene. Nature Nanotechnology 10,459-464

[11] Theron J, Walker J. A. and Cloete T. E, (2008) Nanotechnology and Water Treatment: Applications and Emerging Opportunities, Critical Reviews in Microbiology, 34( 43-69). 9.

[12] The United Nations World Water Development Report (UNWWDR) 2015" Water for a sustainable world"

[13] Wagner L (2007), Water Desalination - Tap into the Liquid Gold. Research report, Mora Associates, Dec 2007 , Nature Nanotechnology 2: ( 663 - 664) .

[14]Zang J,, Cao C, Jie Liu F Y and Zhao X.(2014) Stretchable and High-Performance Supercapacitors with Crumpled Graphene Papers. Scientific Reports 4, Article number: 6492 doi: 10.1038/srep06492.

[15]Zhao,s;Sumedh P; Surwade PS;Zhiting Li and Haitao Liu(2012) Photochemical oxidation of CVD-grown single layer graphene Nanotechnology 23/355703 (6 pp)

\section{Volume 5 Issue 2, February 2016}

